\title{
Grażyna Kobus
}

- Uniwersytet Medyczny w Białymstoku

- e-mail: grazyna.kobus@umb.edu.pl

- ORCID: 0000-0003-1959-7081

\section{Marta Maksimczuk}

- Uniwersytet w Białymstoku

- e-mail:m.maksimczuk@uwb.edu.pl

- ORCID: 0000-0001-7855-5469

\section{МОДЕЛИ И ПРАВОВОЕ РЕГУЛИРОВАНИЕ ЗДРАВООХРАНЕНИЯ В ПОЛЬШЕ И ИТАЛИИ \\ HEALTH CARE MODELS AND LEGAL REGULATION \\ IN POLAND AND ITALY}

\section{Abstract}

- Goal - the paper assessed (main objective) the assumptions of the selected models and legislation regulating health care in the studied countries and examined their impact on the implementation of the constitutional guarantee of access to health services (specific objective).

- Research methodology - the descriptive method was mainly used, with elements of system-legal and formal-legal analysis, as well as cause-and-effect analysis.

- Score/results - main hypothesis was negatively verified (the assumptions of adopted models of health care in Poland and Italy lead to the improvement of constitutional guarantee of access to health services), while the specific one was positively verified (adopted conditions have a significant impact on the functioning of health care in Italy and Poland, in particular during the COVID-19 pandemic).

- Originality/value - organise and systematise the healthcare reality described.

| Keywords: healthcare models, constitutional guarantee of access to health services, Poland, Italy. 


\section{1. Введение}

В статье поднимаются отдельные вопросы здравоохранения в Польше и в Италии. Бесспорно, независимо от временного и пространственного расположения, они имели важное теоретическое и практическое значение. Следует также отметить, что с развитием обществ они стали приобретать все большее значение. В наше время, в связи с глобальными масштабами эпидемии COVID-19, получили особенную значимость и важность.

Субъектом всех систем здравоохранения и одновременно конституционных гарантий здравоохранения является пациент, независимо от существующей в той или другой стране модели. Анализируя литературу, можно выделить по крайней мере два подхода к модельным решениям в сфере здравоохранения. Первый - нормативный подход, в котором основой является здоровье как высшая ценность для человека, а также объект правовой защиты. Второй подход, прагматический - характеризуется тем, что главным пунктом ориентира считается способ финансирования здравоохранения граждан [Bromber, 2015: 50]. Пандемия COVID-19 также доминировала в системе здравоохранения - как с прагматической, так и с нормативной точек зрения. Продолжающийся «локдаун» несомненно окажет негативное влияние на здравоохранение, заставив внести изменения в реализацию государственных услуг, в том числе и в сфере здравоохранения. Законодательство Европейского Союза в своих нормативных актах не налагает единообразных обязательств на государства-члены по организации и финансированию системы здравоохранения [Lenio, 2018: 64].

Основная цель публикации - это презентация основ избранных моделей и норм, регулирующих здравоохранение в Польше и Италии.

Применялся преимущественно описательный метод, дополненный элементами причинно-следственного анализа появившихся зависимостей. Анализируя польскую и зарубежную литературу, авторы использовали преимущественно описательный метод, а при оценке влияния действующего польского и итальянского законодательства на реализацию конституционной гарантии доступа к услугам здравоохранения применяли также элементы системно-правового метода и формально-правового анализа.

Основная гипотеза публикации заключается в том, что предположения принятых моделей здравоохранения в Польше и Италии ведут к улучшению конституционной гарантии доступа к услугам здравоохранения. Подробная гипотеза заключается в том, что предполагаемые условия модели 
оказывают значительное влияние на функционирование здравоохранения в анализируемых странах, в частности, во время пандемии, до настоящего времени.

Основная часть статьи была подчинена реализации так поставленных исследовательских целей в соответствии с выбранной методологией и сформулированными гипотезами. Настоящая работа состоит из трех частей, расположенных в логической последовательности. В первой представлены предположения выбранных моделей здравоохранения с точки зрения нормативного и прагматического подходов. Во второй части представлены законодательные решения, касающиеся здравоохранения в Польше и в Италии. В части третьей была сделана попытка проверить поставленные исследовательские гипотезы. Результаты анализа позволили проверить эти гипотезы, а также сделать некоторые обобщения для сформулирования нескольких предложений, содержащихся в заключении (резюме) настоящего исследования.

\section{2. Модели здравоохранения - основные замечания}

Важным элементом функционирования экономики любой страны является система охраны здоровья, часто называемая системой здравоохранения. Термин «система» в самом общем смысле - это совокупность действий с определенными отношениями между ними, направленными на достижение общей цели. Таким образом, под системой здравоохранения можно понимать «обособленное целое, состоящее из множества различных элементов, которые взаимосвязаны различными отношениями для достижения целей, связанных со здоровьем» [Włodarczyk, Paździoch, 2001: 6]. Согласно определению Всемирной Организации Здравоохранения (ВО3), система состоит из организаций, институций и понесенных затрат, которые ведут к улучшению здоровья людей. Она включает в себя четыре сектора: государственный, юридический, традиционный и неформальный. Его нормальное функционирование зависит от многих факторов, а одним из них является способ финансирования, обусловленный тем, что каждая страна выбирает наиболее подходящую модель системы здравоохранения [Wielicka, 2014: 493].

Литература предмета указывает на четыре нормативные модели здравоохранения: 
1) модель моральная - главной целью которой является святость жизни и здоровья независимо от экономических условий в пользу идеализации прав пациентов, рассматривающая медицинскую профессию как миссионерскую, основанная на предположении, что медицинские работники, т.е. врачи и медицинский персонал с этической и деонтологической точек зрения обязаны заботиться о благе пациента;

2) модель свободного рынка - при которой ответственность за здоровье лежит на пациенте, а объем медицинских услуг зависит от их спроса и предложения;

3) бюрократическая модель - характеризующаяся принципиальным характером, централизованным управлением и контролем в соответствии с обязывающими правовыми нормами; служба здравоохранения содержится за счет бюджетных средств. Сущность системы расположена в учреждениях, которые распоряжаются бюджетными средствами, контролируют и оценивают их расходование;

4) страховая модель - при которой объем медицинских услуг зависит от отношений между пациентом, врачом и страховщиком [Musielak, 2012: 315].

Однако бюрократическая модель не является гарантом равного доступа к медицинским услугам, несмотря на конституционно защищенное право (например, статья 68 Конституции Республики Польша), которое обеспечивает гарантию и равенство в доступе к медицинскому обслуживанию для граждан - независимо от их материального положения органы государственной власти обязаны обеспечить равный доступ к медицинским услугам, финансируемым из государственных средств. Рассмотренная модель направлена на рационализацию деятельности пациентов и экономное управление государственными средствами в соответствии с принципом их целевого и рационального расходования [Musielak, 2012: 315-316]. Модифицированный вариант системы страхования, соединяющий экономическую рациональность (парадигма рационального управления средствами застрахованных, мотивированная этическими предпосылками ответственности за эти средства) с этическим поведением (ответственность за благополучие пациента), является оптимальным решением.

Прагматические модельные решения в области охраны здоровья включают системы, которые на самом деле работали или все еще работают в связи с конкретными решениями законодательства (конституционны- 
ми рамками), приоритетом упорядочения которых является эффективное управление государственными средствами, относящимися к системе здравоохранения. В настоящее время в системе здравоохранения используются четыре модельных решения:

- модель Бисмарка (немецкая система),

- модель Бевериджа (британская, социальная система),

- остаточная модель (американская рыночная система, основой которой является добровольное медицинское страхование),

- модель Семашки (русская) [Paszkowska, 2006].

Основное предположение модели Бисмарка - защитить профессионально активное общество от потери здоровья, что могло бы привести к нарушению общей стабильности [Kautsch, 2001: 31]. Характерной чертой этой системы является способ финансирования сектора здравоохранения. В модели Бисмарка работодатель и работник обязаны платить обязательные взносы на здравоохранение. Модель также предполагает функционирование фондов здравоохранения, которые действуют как страховой фонд [Wielicka, 2014: 493]. Во всех странах, где была принята модель Бисмарка, включая Польшу, медицинская страховка обязательна, распространяется на всех граждан и носит всеобщий характер. За счет общественных средств государство обязано обеспечить бесплатное медицинское обслуживание на минимальном уровне, который определяется корзиной гарантированных медицинских услуг. Граждане могут также пользоваться платной медицинской помощью, предоставляемой негосударственными медицинскими учреждениями, и вступать в медицинские фонды или коммерческие страховые программы, если уровень минимального медицинского обслуживания, предоставляемого государством, недостаточен. Элементы системы Бисмарка, с многочисленными модификациями, можно обнаружить в польской системе здравоохранения, а в Германии обсуждаемая модель существует в своем классическом варианте [Bromber, 2015: 51].

Характерной чертой модели Бевериджа является обязательство государства обеспечить доступ к здравоохранению своим гражданам. В данной модели решения, связанные с финансированием услуг здравоохранения, принимаются государственными учреждениями. Для сектора здравоохранения был создан фонд, финансируемый из государственного бюджета, в основном за счет общих налогов. Все граждане, независимо от их социального статуса, имеют бесплатный доступ к широкому спектру медицинских услуг. 
Модель Бевериджа характеризуется также относительно низкими расходами на здравоохранение, что обусловлено централизованным планированием финансовых ресурсов и контролем расходов на здравоохранение. Систему в ее классическом варианте можно найти в Великобритании. Кроме того, эта система была введена, в частности, в Дании, Финляндии, Греции, Испании, Ирландии, Португалии, Швеции и Италии [Wasiak, Szeląg, 2015: 70].

\section{3. Правовые основы функционирования здравоохранения в Италии}

Современное итальянское здравоохранение, как и вся социально-экономическая система страны, было сформировано правовыми, организационными и политическими решениями с принятием Конституции 1948 года. В разные периоды послевоенных лет она претерпевала свою специфическую эволюцию. Систематическое, начиная с 1960-х годов, увеличение государственных расходов, связанных с финансированием здравоохранения, инициировало также поиск эффективного способа их оптимизации. Особенно быстро, как и в большинстве развитых стран, расходы на функционирование итальянской службы здравоохранения росли в последующие годы XXI века - в том числе благодаря развитию медицинских технологий, а также в связи со старением населения. Эти процессы вызвали действия, направленные на реформирование системы здравоохранения, таким образом, чтобы она была дешевле, но не за счет качества или доступности услуг [Urbaniak, 2014; Wielicka, 2014]. Не следует забывать, что функционирование (и, в частности, финансирование) системы здравоохранения в современной высокоразвитой экономике сильно связано с моделью государственной сферы данной страны и ее национальной экономики в целом. В 1970-х годах, в результате подъема либеральных концепций, все чаще критиковали государство за чрезмерное участие в различных видах деятельности. В результате возникла концепция так называемого нового государственного менеджмента, целью которого было оптимизировать функционирование государственной сферы, используя некоторые решения из частного сектора. В результате система здравоохранения начала также процесс дальнейшей приватизации поставщиков медицинских услуг и коммерциализации некоторых вторичных медицинских услуг [Publiczna..., 2010: 17-25]. В последнее десятилетие прошлого века в Италии, как и в боль- 
шинстве развитых европейских стран, в основном социал-демократические принципы уже систематически внедрялись в экономику и в проводимые реформы системы здравоохранения. Это стало результатом политических изменений того периода и меньшей эффективности неолиберализма как политической теории. Однако во многих случаях изменения, внесенные неолиберализмом в создание сложных и далеко идущих программ, особенно в политике здравоохранения, не были оставлены. Проводимые реформы были все больше направлены на то, чтобы переложить ответственность за финансирование системы здравоохранения с государственных на частные структуры. Введено было частное медицинское страхование и совместное финансирование услуг непосредственно пациентами [Suchecka, 2010: 56-57]. В разное время на рубеже XX и XXI веков в мире продолжались дебаты не только о пропорциях между государственными и частными медицинскими услугами. В большинстве стран Европейского Союза, включая Италию, часто появлялись (в соответствии со взглядами, которых придерживаются в США) соображения о возможности введения в недалеком будущем полностью частного медицинского обслуживания. В мировой дискуссии и в научных публикациях по этому вопросу появились довольно крайние точки зрения - с преобладанием мнения, что это по-прежнему невозможно или нежелательно по экономическим, политическим и моральным причинам. Это произошло [Wójtowicz, Rozynek, 2020], в частности, в результате внимательного анализа следующих ключевых факторов:

1) способа финансирования медицинских услуг;

2) функционирования системы частного медицинского страхования;

3) вопроса: «Смогут ли люди позволить себе пользоваться только частными медицинскими услугами?»;

4) уровня цен на услуги;

5) способа учета интересов людей без финансовых средств;

6) проблем регулирования качества медицинских услуг и продуктов.

В Италии в этом отношении распространено было мнение [Wójtowicz, Rozynek, 2020], высказанное многими мировыми учеными, что полностью индивидуальная медицинская служба, возможно, будет в состоянии предложить по крайней мере такой же уровень медицинской помощи, как государственная или в настоящее время действующая государственно - индивидуальная, однако ее внедрение - дело будущего. С 1 января 1948 года вступила в силу итальянская Конституция (принятая 27 декабря 1947 года), 
вводя принципы социальной защиты, в которые входит право на здравоохранение. Осуществление рассматриваемого законодательного акта создало ответственность за здоровье граждан на стороне государства, то есть привело к созданию соответствующих правовых норм для его обеспечения. Следует указать, что право на получение пособий в основном обусловлено размером финансовых средств, выделяемых государством на осуществление конституционных законов [Luciani, 2003: 63]. Анализируя указанные выше положения Конституции Итальянской Республики, можно сделать вывод, что государство не гарантирует индивидуальный доступ к любым медицинским услугам, однако государственный аппарат обязан гарантировать их минимальный уровень, независимо от финансовых ресурсов, которыми обладает. Нарушение или попрание указанных норм приведет к нарушению субъектной сферы, гарантированной Конституцией по отношению к высшему благу, которым является здоровье.

Следует отметить, что основной закон Европейского Союза не налагает на государства-члены обязательства по единообразной организации и финансированию системы здравоохранения [Трактат о Функционировании Европейского Союза, статья 168(1) $]^{1}$, дополняя только национальную политику. В Италии важнейшими законодательными актами, формирующими модель здравоохранения, являются:

1) Законодательный декрет от 1992 года, изменяющий правила сбора и распределения ресурсов для решения задач общественного здравоохранения;

2) Закон № 662 от 1996 года и Законодательный декрет № 446 от 1997 года перечисляют обязательные взносы, предназначенные для финансирования здравоохранения;

3) Законодательный декрет № 56 от 2000 года, частично передающий обязанность по финансированию системы здравоохранения регионам Италии [Lenio, 2018: 66].

В настоящее время система организации, управления и финансирования здравоохранения в Италии построена по образцу Национальной службы здравоохранения Великобритании. Организационная структура итальянской системы здравоохранения основана на государственном и региональном уровнях. Однако есть и различия, а именно: итальянская

${ }^{1}$ См. Официальный журнал Европейского союза С 326/49, 26.10.2012. 
система здравоохранения характеризуется глубокой централизацией и делегированием компетенций в области здравоохранения. Таким образом, можно наблюдать ограниченное вмешательство государства в деятельность подразделений, ответственных за функционирование системы. Итальянская система здравоохранения ориентирована на три уровня: государственный, региональный и местный [Luciani, 2003]. Каждому из этих уровней поставлены свои задачи. Государство, выполняя свои задачи в основном через министра здравоохранения, контролирует вышеупомянутые уровни, обеспечивает координацию деятельности с целью гарантировать единообразие услуг и распределяет средства, накопленные в Национальном фонде здравоохранения. В компетенцию министра здравоохранения входит определение целей итальянского здравоохранения в Национальном плане здравоохранения, определение рамочного законодательства, гарантирование ресурсов для финансирования здравоохранения на уровне регионов, координация соответствующей системы. Исключительна компетенция по определению объема и уровня льгот в рамках государственной системы здравоохранения. С территориальной точки зрения в Республике Италия мы можем выделить 19 регионов и 2 автономные провинции (Тренто, Больцано), которые совместно несут ответственность с органами государственного управления за организацию и финансирование Национальной службы здравоохранения. Отдельные регионы несут ответственность перед центральным правительством за реализацию и исполнение центральных и региональных целей здравоохранения. Своими действиями отдельные регионы обязаны также указывать потребность в конкретных видах медицинских услуг. Они осуществляют контроль над деятельностью местных подразделений путем определения их организационных структур и надзора за их деятельностью [Urbaniak, 2014: 14; Lenio, 2018: 67].

4. Избранные аспекты функционирования службы здравоохранения в Польше. Реформирование системы здравоохранения

Вместе с системной трансформацией в Польше началось также основательное и политически обусловленное реформирование здравоохранения. В прежней системе (централизованно планируемой) она опиралась на государственное управление и финансировалась из центрального бюджета со стремлением «обеспечения всеобщего доступа к медицинским услугам 
для всех граждан» [Buliński, 2009: 11-17]. По мнению многих исследователей, претензионное отношение общества, сильно привыкшего к модели социального обеспечения государства, вызвало немало осложнений, в том числе и при реформировании медицинской помощи [Watson, 2010: 110; Nojszewska, 2011: 183]. Таким образом, в связи с все еще актуальной дилеммой: полностью публичная или частная? [Wójtowicz, 2020: 155-195], на протяжении всего реформирования (также после 2000 года) сказывались изменения в последующих законах [Dz.U. 2004 Nr 210 poz. 2135; Dz.U. 2017 poz. 1938; Dz.U. 2018 poz. 160], направленных на выбор правильных пропорций между ними. Трудной задачей был также отбор и внедрение новых организационных форм лечебных учреждений - особенно превращение в капитальные общества [Rabiej, 2013: 119], а также изменение в реформах 2011 и 2017 годов нормативных правовых актов финансирования автономных государственных учреждений здравоохранения (поль. SPZOZ) [Chowaniec, 2019: 11-22].

Высшим правовым актом, являющимся основной и неопровержимой базой для внесения любых изменений в систему здравоохранения в Польше, является Конституция Республики Польша. В соответствии со статьей 68 пункт 1 Конституции Республики Польша каждый гражданин имеет право на защиту здоровья [Dz.U. $1997 \mathrm{Nr} 78$ poz. 483]. Кроме того, в соответствии со статьей 68, среди конституционных обязанностей государственных органов в сфере охраны здоровья следует выделить:

1) обеспечение органами государственной власти равного доступа к услугам здравоохранения, финансируемым из государственных средств, для всех граждан, независимо от их материального положения;

2) предоставление государственными органами специальной медицинской помощи детям, беременным женщинам, пожилым людям и инвалидам;

3) контроль эпидемических заболеваний со стороны государственных органов и предотвращение негативных последствий для здоровья от ухудшения состояния окружающей среды;

4) содействие со стороны органов государственной власти развитию физической культуры, особенно в детских и молодежных кружках [Dz.U. $1997 \mathrm{Nr} 78$ poz. 483].

Таким образом, государственные органы обязаны гарантировать гражданам правильно и эффективно функционирующую систему здравоохране- 
ния, что означает, что они должны создать соответствующие условия для реализации права граждан на охрану здоровья. Польская система обязана гарантировать реализацию права граждан на индивидуальную охрану здоровья и доступность финансируемых государством услуг для всех граждан без исключения на основе равенства [Mulawa, 2014: 43].

Задачи в области здравоохранения в рамках выполнения конституционного обязательства по обеспечению доступности здравоохранения для польских граждан законодатель возложил на: органы государственного управления, органы местного самоуправления и Национальный фонд здравоохранения (НФ3, поль. NFZ). «Закон о медицинских услугах, финансируемых из государственных средств», среди задач, которые должны выполнять государственные органы в рамках обеспечения равного доступа граждан к медицинским услугам, указывает:

- создание условий, способствующих функционированию системы здравоохранения;

- анализ и оценку потребностей общества в здоровье, а также факторов, вызывающих изменения в здоровье граждан;

- продвижение здорового образа жизни и профилактика здоровья;

- финансирование здравоохранения в порядке и в соответствии с правилами, определенными настоящим Законом [Mulawa, 2014: 45-46].

В соответствии со статьей 162 раздел 2 и статьей 163 раздел 1 «Закона о медицинских услугах, финансируемых из государственных средств», выполнение этих задач основывалось на принципах: целенаправленности, экономии, законности и надежности. В соответствии со статьей 163 «Закона об услугах здравоохранения, финансируемых из общественных фондов», министр, уполномоченный по вопросам здравоохранения, осуществляет надзор за деятельностью: Национального фонда здравоохранения, бенефициаров, выполняющих контракты с этим Фондом, организаций, которым этим фондом поручено выполнение определенных мероприятий, и аптек в области возмещения стоимости лекарств. Министр осуществляет надзор, руководствуясь критериями целенаправленности, экономичности, законности и надежности. При анализе и оценке выполнения задач в сфере здравоохранения используются критерии административного контроля. В ситуации, когда оценивается выполнение задач в области здравоохранения подразделениями, относящимися к сектору государственных финансов, следует принимать во внимание принципы финансового управления, 
которые определены положениями «Закона о государственных финансах» [Mulawa, 2014: 45-46].

Время ожидания медицинской помощи является основным показателем ее качества. Однако, как и другие факторы, используемые для измерения доступа к медицинским услугам, оно имеет множество ограничений. Это затрудняет получение достоверных выводов о фактическом состоянии доступности таких услуг [Nyczaj, Wasilewski, Dzięgielewski, 2017: 43-51]. Поэтому для ее измерения практика использует не один, а одновременно несколько индикаторов:

1) время ожидания;

2) количество специализированных клиник с контрактом НФЗ и без него;

3) доля госпитализаций, финансируемых НФЗ, в общем количестве госпитализаций пациентов, проживающих в округе;

4) доля посещений амбулаторных специализированных клиник, финансируемых НФЗ, в общем количестве посещений амбулаторных специализированных клиник в округе;

5) количество медицинских услуг, оказанных в отделениях скорой помощи и отделениях неотложной помощи больниц.

Время ожидания медицинских услуг важно при рассмотрении всех аспектов состояния здравоохранения в контексте оценки реализации политики здравоохранения. Правовая основа его использования вытекает из Закона от 27 августа 2004 года «О медицинских услугах, финансируемых из государственных средств» (Dz.U. 2008 Nr 164 poz. 1027, z późn. $\mathrm{zm}$.). Актом о применении упомянутого закона является Постановление Министра здравоохранения от 26 сентября 2005 года «О медицинских критериях, которым должны следовать поставщики медицинских услуг при внесении бенефициаров в списки ожидания на оказание медицинских услуг» (Dz.U.Nr 200 poz. 1661), здесь и далее упоминаются как списки ожидающих.

Однако результаты эмпирических исследований и данные Центрального статистического управления за 2013-2014 годы ясно показывают, что реформы здравоохранения, проведенные до 2017 года, не привели к явному улучшению уровня всех вышеупомянутых индикаторов доступа к государственным больничным услугам и амбулаторной специализированной помощи в Польше [Nyczaj, Wasilewski, Dzięgielewski, 2017: 43-51]. Поэтому улучшения конституционной доступности услуг здравоохранения в Польше 
можно ожидать только от практической проверки предположений другой реформы функционирования и финансирования больничного лечения, введенной в 2017 году [Jarosz-Żukowska, 2020: 159-174].

\section{5. Заключение}

В заключение следует отметить, что поставленные цели исследования были достигнуты. Первая, главная, была направлена на «представление предпосылок выбранных моделей и положений, регулирующих здравоохранение в Польше и Италии». Вторая, подробная, заключалась в «исследовании и оценке модельных решений и их влияния на реализацию конституционной гарантии доступа к медицинским услугам в анализируемых странах». Были также проверены выдвинутые гипотезы исследования. Главная, предполагающая, «что принятые модели здравоохранения в Польше и Италии ведут к улучшению конституционной гарантии доступа к медицинским услугам», проверена негативно. Подробная гипотеза, согласно которой «условия принятой модели оказывают существенное влияние на функционирование здравоохранения в анализируемых странах, в частности в период пандемии COVID-19 до настоящего времени», проверена положительно.

Проведенный анализ позволил ввести некоторые обобщения, относящиеся к ситуации служб здравоохранения исследуемых стран. Они позволили сформулировать следующие выводы:

1) Несмотря на существование множества моделей здравоохранения и возможность анализа мировой практики применения заложенных в них решений, в области выбора направлений реформирования служб здравоохранения отдельных стран остается много сложных дилемм, что наблюдается также в Польше.

2) Анализируя модельные решения здравоохранения, можно заметить, что наибольший объем доступа содержит модель Бисмарка, хотя в принципе модель Семашко, в которой наблюдается значительное вмешательство государства в здравоохранение, тоже отвечает большинству этих требований.

3) Конституционное право на медицинское обслуживание, а также законодательные нормы в большинстве стран (включая рассмотренные здесь: Польшу и Италию) не являются полностью удовлетворительными и равными для полного доступа к медицинским услугам и процедурам. 
Однако, в принципе они обеспечивают гражданам достаточную гарантию чувства безопасности здоровья.

4) Типовые решения в области здравоохранения, принятые в той или иной стране, определяют объем и степень доступа граждан к медицинским услугам. Рассмотрение реализации реформ здравоохранения, исходя из предыдущего опыта и последующих попыток модификации, показывают, что ни одно государство не может гарантировать своим гражданам полный доступ к медицинскому обслуживанию. Они вынуждены нести связанные с этим дополнительные расходы.

5) В целом, социально-экономическая практика (конечно, в настоящее время и в отношении здравоохранения) всегда была, хотя и не обязательно быстро, конечным верификатором проверки фактической полезности принятых модельных решений. Здесь также имеет значение фактор времени (длинный или короткий временной горизонт). Изначально даже хорошо работающие на практике модельные решения могут оказаться не вполне или вообще неэффективными в новых, динамически изменяющихся условиях их функционирования (например, особенно в периоды глубоких экономических спадов, с которыми в прошлом часто приходилось сталкиваться).

6) Нельзя также не учитывать в представленных здесь рассуждениях условия конкретного кризиса (так называемого коронакризиса), вызванного эпидемией COVID-19. Конечно, еще слишком рано для полной и тщательной оценки того, как службы здравоохранения отдельных стран (в том числе рассмотренных здесь: польской и итальянской) преодолевают эти современные, гораздо более сложные проблемы. В настоящее время можно дать лишь предварительную оценку эффективности их работы по преодолению отдельных волн (фаз) эпидемии COVID-19.

7) Слишком далеко идущие обобщения и выводы все еще были бы неоправданными - тем более, что наблюдения и анализы на сегодняшний день уже показали гораздо большую полезность польской модели здравоохранения по сравнению с итальянской в условиях «коронакризиса» (определенные и в целом неоспоримые признаки этого можно увидеть, в частности, на ранних этапах этой эпидемии).

8) Необходимо проводить дальнейшие, гораздо более углубленные междисциплинарные исследования этого специфического кризиса и возникшей ситуации в сфере здравоохранения во всем мире и в изучаемых здесь странах. 
9) Эпидемия COVID-19 и последовавший за ней глобальный экономический кризис, несомненно, оказали огромное влияние на функционирование служб здравоохранения большинства стран (в том числе и Польше) - особенно повлияли на направления дальнейшей реформы финансирования здравоохранения. Возврата к системе общественного здравоохранения скорее не стоит ожидать, но полностью частное медицинское обслуживание это тоже мало вероятный сценарий. Таким образом, медицинская служба останется государственно-частной.

\section{І литература}

Bromber P., 2014, Rola i funkcjonowanie NFZ w systemie ochrony zdrowia, „Zeszyty Naukowe Uniwersytetu Szczecińskiego", nr 802, s. 1-17.

Buliński L., 2009, Polityczne uwarunkowania zmian w ochronie zdrowia. Sektor niepubliczny, Warszawa.

Chowaniec M., Krawczyk N., 2019, Specyfika zarządzania finansami w samodzielnych publicznych zakładach opieki zdrowotnej w Polsce, „Zeszyty Naukowe Wyższej Szkoły Ekonomii i Informatyki w Krakowie”, z. 15, s. 11-22.

Dziubińska M. i in., 2014, Finansowanie świadczeń opieki zdrowotnej, Warszawa 2014. Jarosz-Żukowska S., 2020, Konstytucyjne prawo dostępu do świadczeń opieki zdrowotnej finansowanej ze środków publicznych po wprowadzeniu „sieci” szpitali. Uwagi o racjonalności ustawodawcy, „Acta Universitatis Wratislaviensis”, nr 3978, Przegląd Prawa i Administracji, cz. 1-2, s. 159-174.

Kautsch M., Whitfield M., Klich J. (red.), 2001, Zarządzanie w opiece zdrowotnej, Kraków. Konstytucja Republiki Włoskiej z dnia 22 grudnia 1947, Gazetta Ufficiale de 27 dicembre 1947, n. 298.

Konstytucja Rzeczypospolitej Polskiej z dnia 2 kwietnia 1997 r., Dz.U. 1997 Nr 78 poz. 483.

Lenio P., 2018, Prawne aspekty finansowania systemu ochrony zdrowia we Włoszech, „Kwartalnik Prawno-Finansowy”, nr 1, s. 63-82.

Luciani M., 2003, Brevi note sul diritto alla salute nella piu recente giurisprudenza costituzionale, [w:] Il diritto della salute alle soglie del terzo millennio. Profili di irdine etico, giuridicoed economic, ed. L. Chieffi, Torino.

Mulawa M., Równy dostęp do świadczeń opieki zdrowotnej w kontekście perspektywy wprowadzenia dodatkowych ubezpieczeń zdrowotnych, [w:] Finansowanie świadczeń opieki zdrowotnej, red. M. Dziubińska et al., Warszawa 2014.

Musielak M., 2012, Etyczne aspekty zarządzania stużba zdrowia w Polsce, „Nowiny Lekarskie", nr 4. 
Nojszewska E., 2011, System ochrony zdrowia w Polsce, Warszawa.

Nyczaj K., Wasilewski D., Dzięgielewski M., 2017, Problematyka pomiaru dostępu do publicznych świadczeń szpitalnych i ambulatoryjnej opieki specjalistycznej (AOS), „Menagement Sciences. Nauki o Zarządzaniu”, nr 3 (32), s. 43-51.

Paszkowska M., 2006, Zarys finansowania systemu zdrowotnego w Polsce, „e-Finanse. Finansowy Kwartalnik Internetowy", nr 3, [on-line] https://finquarterly.com/ archives/?number $=6 \&$ id $=271$ [dostęp: 23.07.2020].

Publiczna czy niepubliczna opieka zdrowia. Koncepcje, regulacje zarządzanie, 2010, red. K. Ryć, A. Sobczak, Warszawa.

Rabiej E., 2013, Formy organizacyjne podmiotów leczniczych - uwarunkowania prawne i ekonomiczne, „Przedsiębiorstwo i Region”, nr 5, s. 100-108.

Suchecka J., 2010, Ekonomika zdrowia i opieki zdrowotnej, Warszawa.

Traktat o Funkcjonowaniu Unii Europejskiej (TFUE).

Urbaniak M., 2014, Aspekty publicznoprawne organizacji i finansowania ochrony zdrowia $w$ Republice Włoskiej, Toruń.

Ustawa z dnia 15 kwietnia 2011 r. o działalności leczniczej (Dz.U. 2018 poz. 160).

Ustawa z dnia 27 marca 2004 r. o świadczeniach opieki zdrowotnej finansowanych ze środków publicznych (DzU. 2004 Nr 210 poz. 2135, z późn. zm.).

Ustawa z dnia 27 sierpnia 2004 r. o świadczeniach opieki zdrowotnej finansowanych ze środków publicznych (Dz.U. 2017 poz. 1938, z późn. zm.).

Wasiak A., Szeląg P., 2015, Wydatki na ochronę zdrowia w Polsce na tle krajów Unii Europejskiej w latach 2007-2011, „Finanse i Prawo Finansowe. Journal and Financial Law. Kwartalnik", t. 2, nr 2, s. 67-85.

Watson P., 2010, Obywatelstwo dla wszystkich? Polityka reform systemu opieki zdrowotnej w Polsce, „Prace Instytutu Profilaktyki Społecznej i Resocjalizacji”, nr 15.

Wielicka K., 2014, Zarys funkcjonowania systemów opieki zdrowotnej w wybranych krajach Unii Europejskiej, „Zeszyty Naukowe Politechniki Śląskiej”, z. 70, nr 1909, seria: Organizacja i Zarządzanie, s. 491-504.

Włodarczyk C., Paździoch S., 2001, Systemy zdrowotne, Kraków.

Wójtowicz S., Rozynek K., 2020, Całkowicie prywatna opieka medyczna - próba zarysu, „Ekonomia - Wroclaw Economic Review”, nr 26/1, s. 155-195. 